\title{
Evaluation of selected ultrasonography parameters in the second stage of labor in prediction mode of delivery
}

\author{
Magdalena Ciaciura-Jarno ${ }^{1}$, Wojciech Cnota ${ }^{1}$, Dominik Wójtowicz ${ }^{1}$, \\ Anna Niesłuchowska-Hoxha ${ }^{1}$, Aleksandra Ruci ${ }^{1}$, Rafał Kierach ${ }^{1}$, Aleksandra Stępień ${ }^{1}$, \\ Agnieszka Nowak ${ }^{2}$, Patrycja Sodowska ${ }^{1}$ \\ ${ }^{1}$ Clinical Ward of Obstetrics and Gynecology in Ruda Śląska, Silesian Medical University, Poland \\ ${ }^{2}$ Ward of Gynecology and Obstetrics, Silesian Hospital, Cieszyn, Poland
}

\begin{abstract}
Objectives: The aim of the study is to determine the usefulness of ultrasound parameters in the second stage of labor in prediction of the method of delivery and to evaluate the benefits to be derived from this study.

Material and methods: Ultrasound scan was performed with Convex transabdominal probe on 68 pregnant women in labor at term with fetuses in cephalic presentation at the beginning of the second stage of labor and parameters such as angle of progression, head progression distance, head-symphysis distance and head-perineum distance were measured. The parameters were observed in two scans: a midline scan visualizing the pubic symphysis with the head of the fetus and a transverse scan approximately $1-2 \mathrm{~cm}$ below the pubic symphysis visualizing the head of the fetus.

Results: The ultrasound parameters measured at the beginning of the second stage of labor, differed in the group in which women have delivered vaginally and in the group, in which caesarean section was performed: angle of progression and head progression distance were greater in group of women who delivered naturally and head-perineum distance and head-symphysis distance were smaller in this group. Some relations between each measured parameter and time left to delivery were observed as well as strong relations among parameters were also observed.

Conclusions: Intrapartum sonography is a useful and objective tool to assess the progress of labor. Transperineal ultrasound scans performed in the second stage of labor may play a role in making the decision about the mode of delivery.

Key words: intrapartum sonography, transperineum sonography, translabia sonography, labor prediction
\end{abstract}

Ginekologia Polska 2016; 87, 6: 448-453

\section{INTRODUCTION}

In the recent years, there has been a definite increase in a ratio of caesarean sections in Poland. The upward trend was observed constantly between 1999 when the rate was $18.2 \%$ and 2006 when it increased to $28.8 \%$ [1]. According to Peristat the ratio of caesarean sections performed in our country changed from approx. $27 \%$ in 2004 to o $34 \%$ in 2010. Their fastest growth in Europe in those years was observed in the countries of Central and Eastern Europe, Poland included [2].

A caesarean section entails a bigger threat to the health and life of the woman giving birth compared to natural childbirth. Since the trend of increasing ratio of caesarean sections is an alarming one, it is important that the assessment of indications is not treated lightly. On the other hand, postponing the decision on the surgical delivery when it is necessary deteriorates the prognoses for the child and causes anxiety in the laboring woman [3]. In view of these facts, there is a particular need to find and use precise yet simple ways to monitor the course of delivery.

Currently, the internal digital vaginal exam is the basis for the assessment of stage and progress of labor. However, there is much evidence that palpation performed during childbirth is inaccurate and does not allow for precise deter- 
mining the progression of head in the birth canal and that it is prone to a high number of errors in the evaluation of position and lie of the presenting part in both the first and second stage of labor [4].

Transperineal ultrasound (TPU) is more easily accepted by the laboring woman than palpation - in the study by Torkildsen et al. only one patient in a hundred and ten reported discomfort [5]. TPU is safer in the state after the rupture of amniotic membranes - it may cause less intrauterine infections, plays a role in examining poorly cooperative patients and in the absence of patient's the consent to palpation.

During the palpation examination in labor, an obstetrician usually assesses the head station in birth canal using a numerical system referring to the line connecting the ischial spines and measuring in centimeters the distance from the presenting part where -1 means the presenting part 1 centimeter above the interspinal line and +1 one centimeter below it. In the study by Dupuis et al. performed on a phantom, residents made mistakes in $50-88 \%$ of cases and obstetricians in $36-80 \%$ (depending on the position of the head of the fetus) in determining the head station in birth canal measured with the numerical system [6].

In the study by Souka et al. the examiners incorrectly determined the head position in $60.7 \%$ of cases in the first stage of labor and in $30.8 \%$ in the second stage of labor [7].

Barbera et al. reconstructed the female pelvis based on $70 \mathrm{CT}$ examinations of pelvises of non-pregnant women and determined that the angle between the long axis of the pubic symphysis and the line connecting the lower edge of the symphysis with the interspinal line is 99 degrees [8]. Henrich et al., also based on the reconstruction of female pelvis with computed tomography, determined that the average distance from the line perpendicular to the long axis of pubic symphysis passing through the median plane of the body and a line parallel to it passing through the ischial spine is $3 \mathrm{~cm}$ [9]. The findings from these computed tomography studies can be used in ultrasound examinations and the measured parameters can be converted into the results of a palpation exam for the progression of the presenting part in the birth canal, and vice versa.

In 2010, Simpkin P. et al., drew a strong conclusion that ultrasound is by far the best tool to determine the position of the fetus and has the potential to improve performance [10].

The work carried out to date evaluating the use of both $2 \mathrm{D}$ and $3 \mathrm{D}$ ultrasound has defined the objective ways to measure the engagement of the head in the birth canal, using the following:

- angle of progression (AoP);

- head progression distance (HPrD);

- head-symphysis distance (HSD);

- head-perineum distance (HPerD).
Molina and Nicholaides write that intrapartum ultrasound may help evaluate whether pregnancy will end in a vaginal delivery and $G$ hi et al. reports that the assessment of head progression in the birth canal during the second stage of labor may play a role in predicting the manner of delivery $[4,11]$.

These facts and reports prompted us to conduct our own research and verify whether in clinical practice these parameters could be useful in making decisions on the execution of a caesarean section in the second stage of labor.

\section{PURPOSE OF THE STUDY}

The study aims to assess the efficiency of ultrasound parameters in the second stage of labor in predicting the methods of delivery and to estimate the benefits to be derived from this research.

\section{MATERIAL AND METHODS}

The ultrasound examinations were performed in the delivery room with Voluson 730 Expert ultrasound machine with AB2-7 transducer on laboring women immediately following the time of midwife or doctor examining and declaring a complete cervical dilatation. The study was conducted on 68 women aged 15 to 39 years (average: 28 years), giving birth at term, fetuses in cephalic longitudinal presentation. Among the subjects, 36 were primiparas, 32 multiparas. The average weight of a newborn was $3431 \mathrm{~g}$ (min. $2400 \mathrm{~g}$, $\max .4215 \mathrm{~g}$ ).

Inclusion criteria:

- gestational age at least $37+0$ weeks;

- Iongitudinal cephalic fetus presentation;

- singleton pregnancy.

Exclusion criteria:

- gestational age less than $37+0$ weeks;

- other than longitudinal cephalic fetus presentation;

- multiple pregnancy;

- defects of the uterus;

- condition after uterus surgery;

- epidural anesthesia.

Parameters were measured performing two scans:

- a scan on the midsagittal plane of the woman in labor visualizing the pubic symphysis along with the head of the fetus with the following assessed:

- angle of progression, i.e. the angle between the long axis of the symphysis pubis and the line in midsagittal plane passing through the lowest point of the symphysis and tangent to the skull of the fetus (Figure 1);

- head progression distance i.e. the shortest distance between the line perpendicular to the long axis of the symphysis pubis contained in the midsagittal plane and the presenting point (Figure 2); 


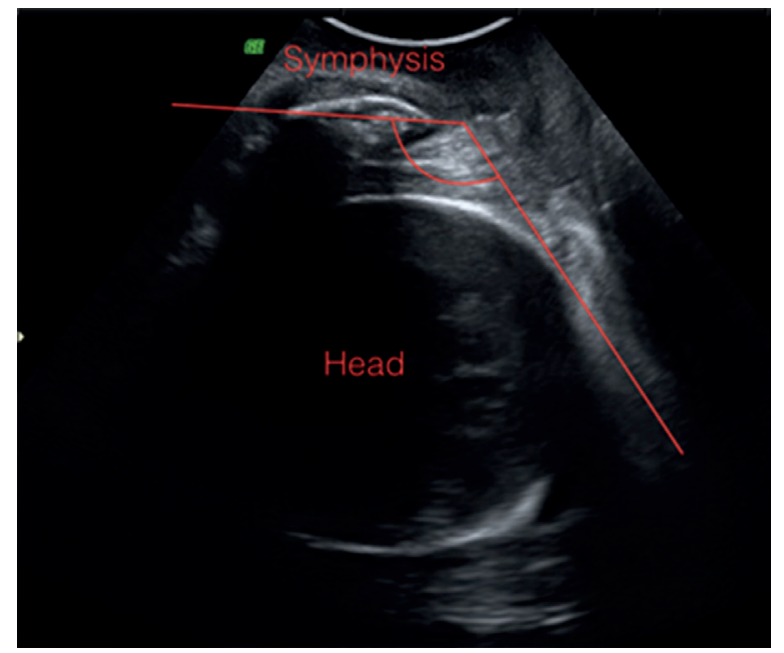

Figure 1. Angle of progression

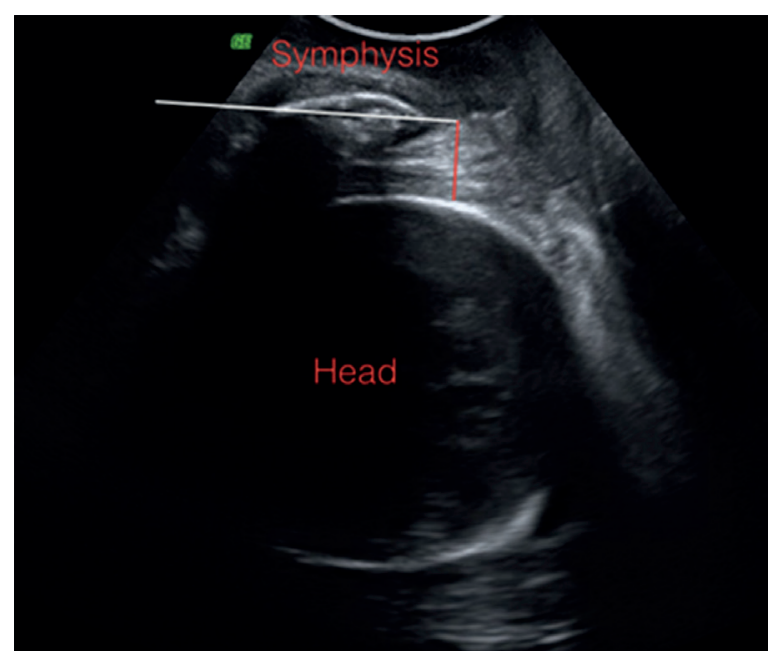

Figure 3. Head-symphysis distance

- head-symphysis distance i.e. the shortest section perpendicular to the long axis of the pubic symphysis connecting the lower edge of the symphysis and the skull of the fetus (Figure 3);

- a scan performed transversely approx. 1-2 cm downwards from the pubic symphysis visualizing the head of the fetus with the following assessed:

- head-perineum distance i.e. the shortest distance between the presenting point of the skull and perineum (the transducer) (Figure 4).

Patients have been divided into two groups after delivery upon the manner of birth: one group consisted of patients who had a caesarean section performed, another group of patients, who delivered naturally.

The parameters were assessed within both groups and compared between them.

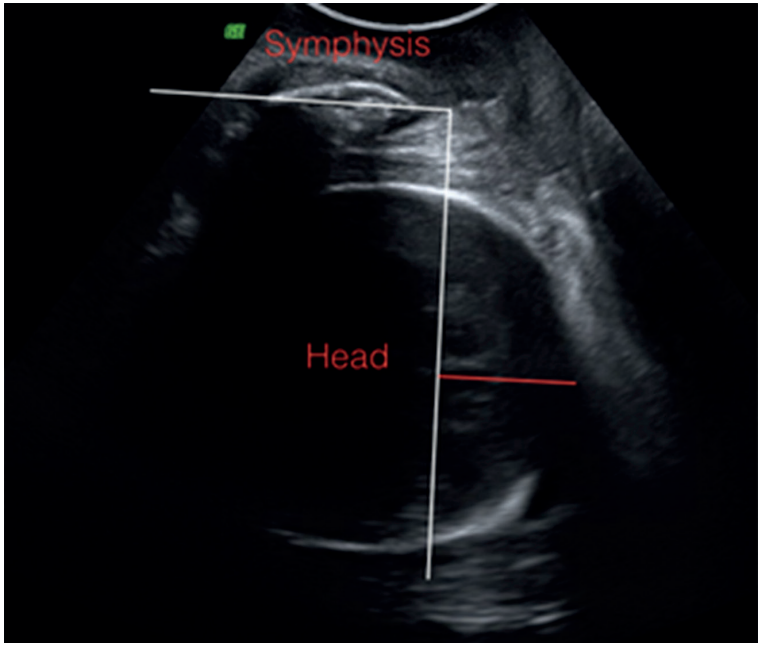

Figure 2. Head progression distance

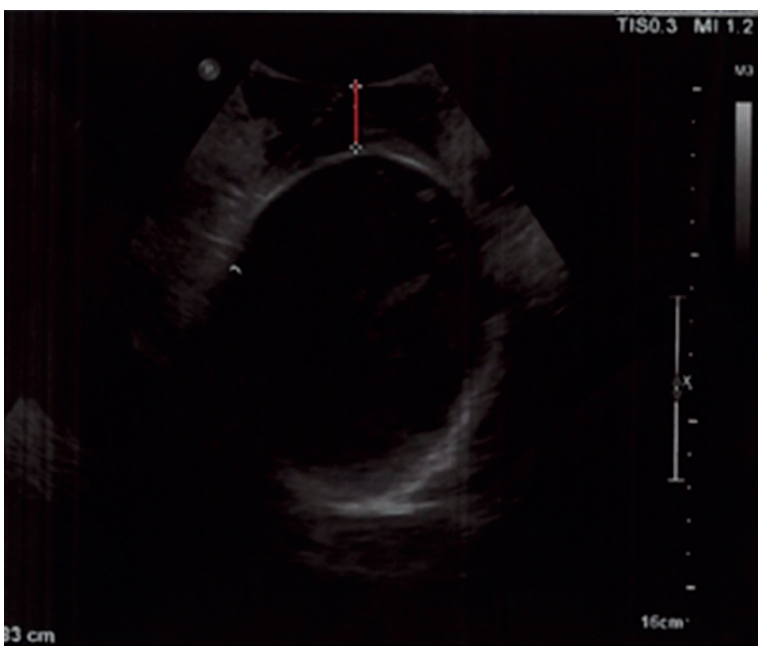

Figure 4. Head-perineum distance

In one group, there were 60 deliveries and the other 8 caesarean sections performed for lack of progress in labor. The person deciding upon the execution of the caesarean section was not privy to the results of the ultrasound examination. Also assessed was the correlation of the measured parameters with the time elapsed from the measurement to the birth of the child and the correlation coefficient of the measured parameters to one another.

\section{RESULTS}

Arithmetic means and medians for all measured parameters differed for the two groups.

All patients whose value for the head-symphysis distance was below $1.78 \mathrm{~cm}$ delivered naturally and 21 patients (35\%) who delivered naturally had this value above $1.78 \mathrm{~cm}$ at the time of complete dilatation. 


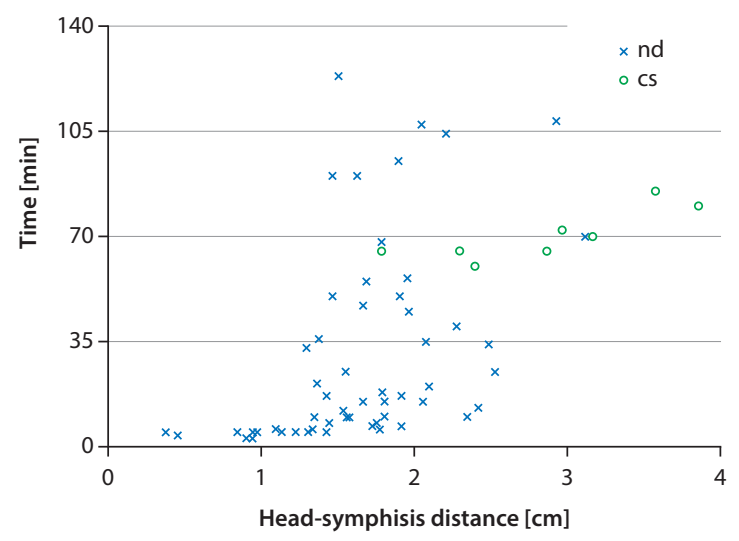

Figure 5. Time to delivery and head-symphysis distance; nd - natural delivery; cs - caesarean section

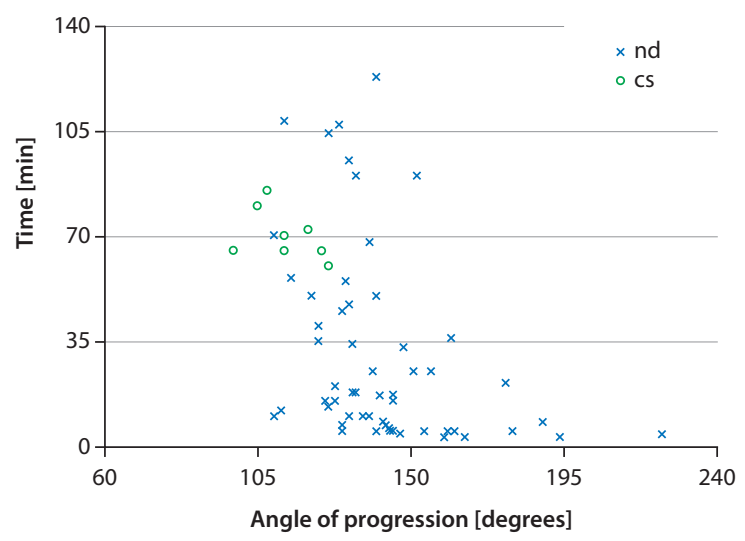

Figure 7. Time to delivery and angle of progression; nd - natural delivery; cs - caesarean section

The arithmetic mean for the head-symphysis distance is $1.62 \mathrm{~cm}$ in the group where patients delivered naturally and represents nearly $60 \%$ of the average value in the other group of patients who had caesarean section performed $(2.86 \mathrm{~cm})$. The median value for the first group is $1.6 \mathrm{~cm}$, while the median value for the second group is $2.91 \mathrm{~cm}$ (Figure 5).

All patients whose value for the head progression distance was above $3.43 \mathrm{~cm}$ delivered naturally and 12 patients (20\%) who delivered naturally had this value below $3.43 \mathrm{~cm}$ at the time of complete dilatation.

The arithmetic mean for the head progression distance is $4.47 \mathrm{~cm}$ in the group where patients delivered naturally and is nearly twice as high as the value of $2.34 \mathrm{~cm}$ calculated for the other group of patients who had caesarean section performed. The median value for the first group is $4.39 \mathrm{~cm}$, while the median value for the second group is $2.47 \mathrm{~cm}$ (Figure 6).

All patients with an angle of progression above $126 \mathrm{de}-$ grees delivered naturally and for 9 patients (15\%) of those who delivered naturally this value was less than 126 degrees at the time of complete dilatation.

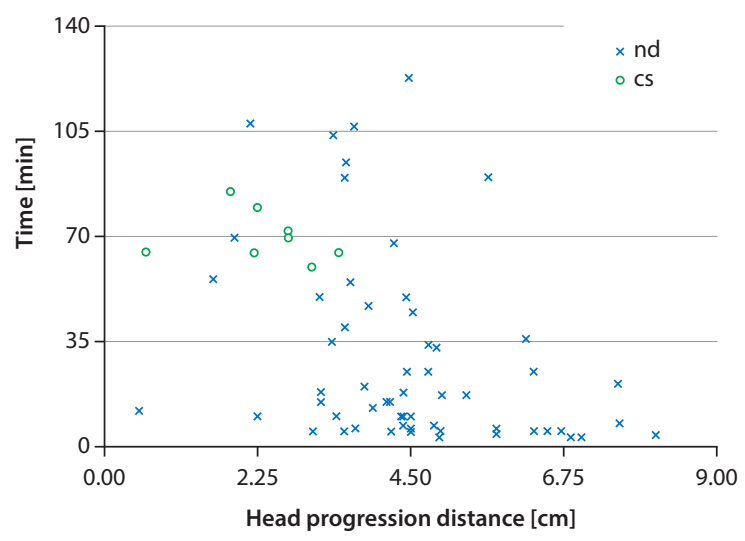

Figure 6. Time to delivery and head progression distance; nd — natural delivery; cs - caesarean section

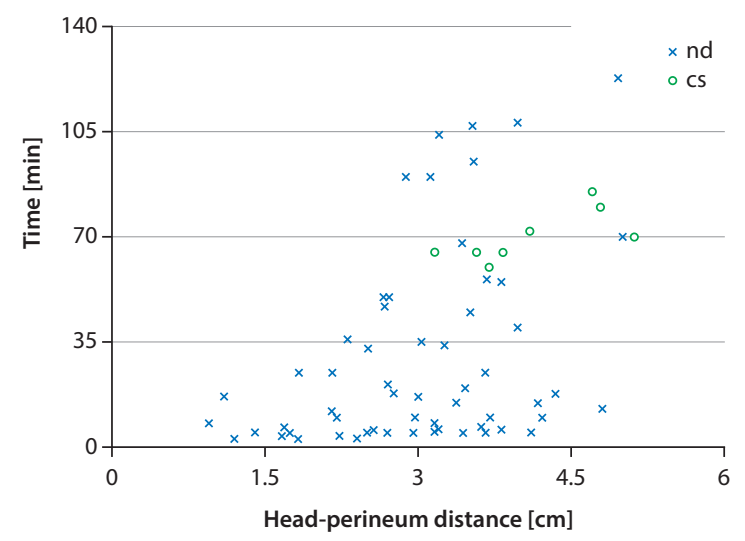

Figure 8. Time to delivery and head-perineum distance; nd — natural delivery; cs - caesarean section

The arithmetic mean for the angle of progression is 142.5 degrees (the median 139.5 degrees) in the group where patients delivered naturally and 113.4 degrees in the group where a caesarean section was performed (the median 113 degrees) (Figure 7).

All patients whose value for the head-perineum distance was below $3.16 \mathrm{~cm}$ delivered naturally and 27 patients (45\%) who delivered naturally had this value above $3.16 \mathrm{~cm}$ at the time of complete dilatation.

The arithmetic mean for the head-perineum distance is $3 \mathrm{~cm}$ (the median $3.08 \mathrm{~cm}$ ) in the group where patients delivered naturally and $4.12 \mathrm{~cm}$ in the group of patients who had caesarean section performed (the median $3.96 \mathrm{~cm}$ ) (Figure 8).

The correlation coefficient for the head-symphysis distance to the time remaining until delivery is the highest among all the correlation coefficients for the measured parameters to the time remaining until delivery and equals 0.57 (Table 1).

All the ultrasound parameters measured correlate strongly with each other, where the highest correlation 


\begin{tabular}{|c|c|c|c|c|}
\hline Correlation coefficient & $\begin{array}{l}\text { Head-symphysis } \\
\text { distance }\end{array}$ & $\begin{array}{l}\text { Head progression } \\
\text { distance }\end{array}$ & $\begin{array}{c}\text { Angle } \\
\text { of progression }\end{array}$ & $\begin{array}{l}\text { Head-perineum } \\
\text { distance }\end{array}$ \\
\hline Parameter to the time from measurement to delivery & 0.5702 & -0.4242 & -0.4787 & 0.4783 \\
\hline HSD to the given value & & -0.6465 & -0.7611 & 0.6344 \\
\hline $\mathrm{HPrD}$ to the given value & & & 0.9061 & -0.5875 \\
\hline AoP to the given value & & & & -0.6038 \\
\hline
\end{tabular}

coefficient of 0.906 is observed for the parameters: head progression distance and angle of progression and the second highest correlation coefficient is observed for head-symphysis distance and angle of progression at an absolute value of 0.76 .

All multiparas delivered naturally, caesarean sections were performed only in the group of primiparas.

\section{DISCUSSION}

The study shows that all 4 measured parameters at the onset of the second stage of labor strongly correlate with each other. These results agree with those reported in the literature, which assess that the above parameters have a strong correlation between each other and a weak correlation to the palpation exam [12]. This study also presents a correlation between each tested parameter and the time remaining until delivery. In our study, the time until the execution of a caesarean section used for the calculation of the correlation coefficient is artificial, as it refers to the time until a decision on the execution of the operation is taken, and therefore depends on the person taking this decision. In accordance with the guidelines of PTG (Polish Gynecological Society) recommending an examination of the laboring woman an hour after compete dilatation in order to evaluate the progress of labor and to estimate whether there are chances for a natural delivery, we may assume that the operations would be performed at least 60 minutes into the second stage of labor. The issue here is about caesarean sections performed for lack of progress in labor, such as those mentioned in this work [13]. In all cases in the collected material, caesarean sections were performed at least an hour from the compete dilatation of the cervix.

Youssef et al. examines the head-symphysis distance on 47 laboring women and determines this parameter to be easy to measure and strongly negatively correlating with the palpation test and evaluation of the angle of progression [14]. In another study, the author evaluates, on 86 laboring women, the accuracy of measurements made using 2D and 3D ultrasound and states no difference between them [15]. In our results, the correlation coefficient for the two above parameters is 0.76 , confirming the observation that this parameter correlates well with the angle of progression. This is the newest of the intrapartum ultrasound parameters described in the literature, characterized by simplicity of measurement.

Ghi et al. analyses 30 volumes created using 4D ultrasound measurements and determines a good repeatability for the head progression distance in assessing the engagement of the head in the birth canal [16]. Our findings show that this parameter has the highest correlation coefficient (0.91) with the best studied angle of progression yet. In this way, this work confirms a good repeatability of this parameter.

The angle of progression is the parameter the most publications have been devoted to so far. In 2009, Barbera et al. measured the above parameter on 23 women in the second stage of labor and in the published results in all cases where the angle was greater than 120 degrees a natural delivery followed, while in the cases where a caesarean section was performed (6 laboring women) the angle averaged 108 degrees. The measurement of the angle of the progression performed translabially was demonstrated to be an objective, accurate and repeatable parameter in the assessment of the engagement of the head in birth canal [17].

Kalache et al. measured the angle of progression in 26 cases of prolonged second stage of labor in occiput anterior position and in a retrospective analysis of material finds that at an angle of 120 degrees $90 \%$ deliveries happened naturally or they were simple successful deliveries with vacuum extraction. The angle of progression was deemed to be an objective parameter in anticipating the manner of delivery in the case of a prolonged second stage at occiput anterior position and the use of this parameter may enable better decision-making on the issue of how to resolve the pregnancy [18].

In our study, at a slightly greater angle of progression than in the study of Barbera et al., i.e. at 126 degrees or more, all deliveries happened naturally. Among the natural deliveries, there were nine cases where the value of the angle was below 126 degrees, which represented 15\% of natural deliveries. Another analogy to this work, is the value of the angle in the cases where a caesarean section was performed, averaging 113 degrees. 
Ghi et al. specifies this parameter as one of the two most repeatable in the assessment of the head engagement in the birth canal [16]. In another work, Ghi et al. measures the above parameter on 71 laboring women in the second stage of labor and determines that in cases of spontaneous delivery the angle of progression was larger at the onset of the second stage of labor compared to the women who had an operation performed. The results of our study coincide with the results of the above work.

Ghi et al. concludes that this parameter measured in the second stage of labor may play a role in predicting the manner of resolving the pregnancy [11].

Torkildsen et al. examines the values of the angle of progression and the head-perineum distance on 110 primiparas in the first stage of labor by using 2D and 3D ultrasound and concludes that using both parameters one may predict the manner of delivery with similar predictor scores for both techniques [5]. Eggebo et al. examine the same parameters on 150 primiparas in the prolonged first stage of labor. They draw the conclusions that both parameters contribute important information about the likelihood of a vaginal delivery and correlate with the time until the completion of delivery [19].

Ghi notes that translabial ultrasound is equivalent to a palpation examination and may be useful in diagnosing the lack of progress of labor during the second stage of labor and by the implementation operational delivery [20].

Intrapartum ultrasound aims to improve the diagnosis of protracted labor and thus prevent the execution of caesarean sections in unnecessary cases when the progress in labor exists, as well as to avoid late execution of a caesarean section, in situations where the no progress in labor occurs. Another objective is to improve the safety of vaginal assisted deliveries.

Sherer et al., using ultrasound, show in their study that $58 \%$ of obstetricians and $33 \%$ of residents correctly evaluate the position of the head upon palpation examination during active labor. Intrapartum ultrasound may also serve as a tool in the study of obstetrics for physicians in training [21].

\section{CONCLUSIONS}

Intrapartum ultrasound examination is a useful, an objective tool to assess the progress of labor.

Translabial ultrasound examination performed during the second stage of labor may play a role in deciding how to resolve the pregnancy.

The research above may also contribute to shortening the second stage of labor for patients who are about to have a caesarean section performed and to performing fewer caesarean sections during the second stage of labor on patients for whom natural delivery is possible.

\section{REFERENCES}

1. Troszyński M, Niemiec T, Wilczyńska A. Cięcie cesarskie - dobrodziejstwo czy zagrożenie? Perinatologia, Neonatologia i Ginekologia. 2008, 1 (1), 8-10.

2. European Perinatal Health Report: Health and Care of Pregnant Woman and Babies in Europe in 2010.

3. Głuszak M, Frącki S, Wielgoś M, Węgrzyn P. Metody oceny postępu porodu we współczesnym położnictwie. Ginekol Pol. 2013, 84 (8), 709-713.

4. Molina FS, Nicolaides KH. Ultrasound in labor and delivery. Fetal Diagn Ther. 2010, 27 (2), 61-67.

5. Torkildsen EA, Salvesen KÅ, EggeboTA. Prediction of delivery mode with transperineal ultrasound in women with prolonged first stage of labor. Ultrasound Obstet Gynecol. 2011, 37 (6), 702-708.

6. Dupuis $\mathrm{O}$, Silveira R, Zentner A, [et al.]. Birth simulator: reliability of transvaginal assessment of fetal head station as defined by the American College of Obstetricians and Gynecologists classification. J Obstet Gynecol. 2005, 192 (3), 868-874.

7. Souka AP, Haritos T, Basayiannis K, [et al.]. Intrapartum ultrasound for the examination of the fetal head position in normal and obstructed labor. Matern Fetal Neonatal Med. 2003, 13 (1): 59-63.

8. Barbera AF, Imani F, Becker T, [et al.]. Anatomic relationship between the pubic symphysis and ischial spines and its clinical significance in the assessment of fetal head engagement and station during labor. Ultrasound Obstet Gynecol. 2009, 33 (3): 320-325

9. Henrich W, Dudenhausen J, Fuchs I, [et al.]. Intrapartum translabial ultrasound (ITU): sonographic landmarks and correlation with successful vacuum extraction. Ultrasound Obstet Gynecol. 2006, 28 (6), 753-760.

10. Simkin P. The fetal occiput posterior position: state of the science and a new perspective. Birth. 2010, 37 (1): 61-71.

11. Ghi $\mathrm{T}$, Youssef A, Maroni E, [et al.]. Intrapartum transperineal ultrasound assessment of fetal head progression in active second stage of labor and mode of delivery. Ultrasound Obstet Gynecol. 2013, 41 (4): 430-435.

12. Tutschek B, Torkildsen EA, EggeboTM. Comparison between ultrasound parameters and clinical examination to assess fetal head station in labor. Ultrasound Obstet Gynecol. 2013, 41 (4): 425-429.

13. Zespół ekspertów PTG. Rekomendacje zespołu ekspertów Polskiego Towarzystwa Ginekologicznego dotyczące opieki okołoporodowej i prowadzenia porodu. Ginekol Pol. 2009, 80 (7), 548-557.

14. Youssef A, Maroni E, Ragusa A, [et al.]. Fetal head-symphysis distance: a simple and reliable ultrasound index of fetal head station in labor. Ultrasound Obstet Gynecol. 2013, 41 (4), 419-424.

15. Youssef A, Bellussi F, Montaguti E, [et al.]. Agreement between two- and three-dimensional transperineal ultrasound methods for assessment of fetal head-symphysis distance in active labor. Ultrasound Obstet Gynecol. 2014, 43 (2): 183-188.

16. Ghi T, Contro E, Farina A, [et al.]. Three-dimensional ultrasound in monitoring progression of labor: a reproducibility study. Ultrasound Obstet Gynecol. 2010, 36 (4): 500-506.

17. Barbera AF, Pombar X, Perugino G, [et al.]. A new method to assess fetal head descent in labor with transperineal ultrasound. Ultrasound Obstet Gynecol. 2009, 33 (3), 313-319.

18. Kalache KD, Dückelmann AM, Michaelis SA, [et al.]. Transperineal ultrasound imaging in prolonged second stage of labor with occipitoanterior presenting fetuses: how well does the'angle of progression' predict the mode of delivery? Ultrasound Obstet Gynecol. 2009, 33 (3), 326-330.

19. Eggebø TM, Hassan WA, Salvesen KÅ, [et al.]. Sonographic prediction of vaginal delivery in prolonged labor: a two-center study. Ultrasound Obstet Gynecol. 2014, 43 (2), 195-201.

20. Ghi T, Farina A, Pedrazzi A, [et al.]. Diagnosis of station and rotation of the fetal head in the second stage of labor with intrapartum translabial ultrasound. Ultrasound Obstet Gynecol. 2009, 33 (3), 331-336.

21. Sherer DM, Miodovnik M, Bradley KS, Langer O. Intrapartum fetal head position I: comparison between transvaginal digital examination and transabdominal ultrasound assessment during the active stage of labor. Ultrasound Obstet Gynecol. 2002, 19 (3), 258-263. 